\title{
Protective approaches against myocardial ischemia reperfusion injury (Review)
}

\author{
XIANCHI LI ${ }^{1}$, MIN LIU ${ }^{2}$, RONGRONG SUN ${ }^{3}$, YI ZENG $^{3}$, SHUANG CHEN $^{1}$ and PEIYING ZHANG ${ }^{1}$ \\ ${ }^{1}$ Department of Cardiology, Xuzhou Central Hospital, The Affiliated Xuzhou Hospital of Medical \\ College of Southeast University; ${ }^{2}$ Department of Cardiology, Xuzhou Clinical School of Xuzhou Medical College; \\ ${ }^{3}$ Xuzhou Clinical Medical College of Nanjing University of Chinese Medicine, Xuzhou, Jiangsu 221009, P.R. China
}

Received March 25, 2016; Accepted September 16, 2016

DOI: $10.3892 / \mathrm{etm} .2016 .3877$

\begin{abstract}
Myocardial ischemia-reperfusion is the leading cause for the events of cardiovascular disease, and is considered as a major contributor to the morbidity and mortality associated with coronary occlusion. The myocardial damage caused by ischemia-reperfusion injury constitutes the primary pathological manifestation of coronary artery disease. It results from the interaction between the substances that accumulate during ischemia and those that are delivered on reperfusion. The level of this damage can range from a small insult resulting in limited myocardial damage to a large injury culminating in myocyte death. Importantly, major ischemia-reperfusion injury to the heart can result in permanent disability or death. Given the worldwide prevalence of coronary artery disease, developing a strategy to provide cardioprotection against ischemia-reperfusion-induced damage is of great importance. Currently, the treatment of reperfusion injury following ischemia is primarily supportive, since no specific target-oriented therapy has been validated thus far. Nevertheless, therapeutic approaches to protect against myocardial ischemia-reperfusion injury remain an active area of investigation given the detrimental effects of this phenomenon.
\end{abstract}

\section{Contents}

1. Introduction

2. Mechanism of myocardial ischemia-reperfusion injury

3. Non-pharmacological protective approaches

4. Pharmacological cardioprotective approaches

5. Conclusion

Correspondence to: Dr Peiying Zhang, Department of Cardiology, Xuzhou Central Hospital, The Affiliated Xuzhou Hospital of Medical College of Southeast University, 199 South Jiefang Road, Xuzhou, Jiangsu 221009, P.R. China

E-mail: zpying58@126.com

Key words: ischemia, myocardial infarction, cardioprotection, reperfusion injury, therapy, conditioning, hypothermia

\section{Introduction}

Acute myocardial infarction (MI), with ST-segment elevation, leads to chronic heart failure and death and results from the sudden blockage of an epicardial coronary artery, thereby causing the supplied myocardium to become ischemic, culminating in permanent damage and scar tissue formation if circulation is not restored. Scar tissue thus formed, lacks the contractile function of the myocardium, and contributes to global left ventricular (LV) dysfunction and finally to failure of the heart (1). Having recognized that it is a blood clot that leads to ST-segment elevated MI, the timely restoration of circulation to the affected myocardium was found to limit the infarct size and also improve myocardial function (2). However, several lines of experimental and clinical evidences showed that reperfusion of the ischemic myocardium causes further damage and this is known as ischemia-reperfusion injury (3). Myocardial ischemia-reperfusion injury refers to myocardial damage that occurs as a result of the interaction between substances that accumulate during ischemia and those that are delivered on the subsequent restoration of blood flow. Although the institution of reperfusion following MI led to a marked reduction in mortality due to MI-related heart failure, there is a significant increase in surviving patients with chronic cardiac dysfunction that resulted from ischemia-reperfusion injury $(4,5)$. Indeed, prolonged ischemia may account for up to $50 \%$ of the final MI size (6) and causes multiple cellular metabolic and ultra-structural changes and in fact, the size of the infarct is a major determinant of the treatment outcomes and thus the primary aim of MI treatment approaches is to reduce the infarct size. The ischemia-reperfusion injury induces inflammatory response, which is initially localized but eventually becomes systemic and induces multi-organ dysfunction and accounts for $30-40 \%$ of intensive care unit mortality. Since reperfusion itself has reduced the MI-related mortality, there has been a paradigm shift in the treatment focus more towards the prevention or amelioration of damage caused by reperfusion. However, it is important to understand the mechanisms of myocardial ischemia-reperfusion injury in order to develop therapies targeting both ischemic and reperfusion damage, to reduce the infarct size, considering that smaller infarct size can lead to better cardiac function, over long-term. Despite a significant amount of research as well as encouraging preclin- 
ical results with multiple agents, most of the clinical trials to prevent reperfusion injury have been disappointing (7) and thus it is important to identify and develop therapies that potentially reduce infarct size. In this review we briefly address the mechanisms underlying the myocardial ischemia-reperfusion injury and the currently available therapies.

\section{Mechanism of myocardial ischemia-reperfusion injury}

The hypoperfused myocardial zone during MI due to the coronary artery blockade is an area of myocardium that is under perfused and this is known as 'the area at risk (AAR)', which rapidly becomes necrotic if reperfusion is not established rapidly. The salvaged myocardium, after reperfusion displays contraction bands, karyolysis, abnormalities of mitochondria such as swelling, and cardiomyocyte membrane disruption in association with inflammation, interstitial hemorrhage and damaged microvasculature (8). Myocardial ischemia-reperfusion injury is a complex process, which involves several interrelated factors, including a decrease in cellular adenosine triphosphate (ATP) levels, accumulation of hydrogen ions, calcium overload, and production of reactive oxygen species (ROS). These factors collectively promote cellular injury and subsequent cardiomyocyte death (Fig. 1).

Initially, ischemia causes mitochondrial oxidative phosphorylation arrest due to a lack of sufficient oxygen, leading to a reduction in ATP production. In order to compensate for this, the affected cardiomyocytes conduct anaerobic glycolysis for ATP production, which leads to the accumulation of protons and lactate, resulting in intracellular acidosis. The elevated intracellular $\mathrm{H}^{+}$activates the plasma membrane $\mathrm{Na}^{+} / \mathrm{H}^{+}$ exchanger, which expels the $\mathrm{H}^{+}$from the cell in exchange for $\mathrm{Na}^{+}$, leading to an increase in intracellular $\mathrm{Na}^{+}$. Reduced activity of $\mathrm{Na}^{+} / \mathrm{K}^{+}$-ATPase due to acid and insufficient ATP, also contributes to the increase in intracellular $\mathrm{Na}^{+}$, which leads to the activation of sarcolemmal $\mathrm{Na}^{+} / \mathrm{Ca}^{2+}$ exchanger (9) and a build up of intracellular $\mathrm{Ca}^{2+}$.

Following reperfusion, respiratory activity, mitochondrial potential, and ATP synthesis are restored and intracellular $\mathrm{pH}$ is restored rapidly to normal level, which causes activation of $\mathrm{Ca}^{2+}$ dependent protease, calpain, which degrades the cytoskeleton and the sarcolemma (10). The increased availability of ATP upon reperfusion in the presence of increased $\mathrm{Ca}^{2+}$ activates sarcoplasmic reticulum (SR) uptake of $\mathrm{Ca}^{2+}$, exceeding the threshold of ryanodine channels, which release $\mathrm{Ca}^{2+}$ into the cytosol. Cyclic repetition of this process leads to $\mathrm{Ca}^{2+}$ oscillations that lead to uncontrolled myofibrillar hypercontraction (11) and also promote opening of the mitochondrial permeability transition pore (mPTP) (12). Opening of mPTP results in mitochondrial matrix swelling, which triggers the rupture of mitochondrial outer membrane and release of mitochondrial intermembrane space contents such as cytochrome $\mathrm{c}$, in to cytosol. Cytochrome $c$ sets the course of promoting the programmed cell death by activating the caspase cascade. The increased $\mathrm{Ca}^{2+}$ oscillations also enhance the activity of xanthine oxidases, promoting the production of ROS, which further exacerbate membrane damage by directly promoting opening of the MPTP (13), and thus contribute to cell death during reperfusion (14). ROS is mostly produced by the different types of cells in the ischemic zone, including the injured myocytes, endothelial cells and neutrophils. Neutrophils entering the ischemic zone further aggravate the cellular damage by releasing inflammatory mediators, causing microvascular obstruction and local and eventually systemic inflammation (15).

\section{Non-pharmacological protective approaches}

The complexities of events that underlie the ischemia-reperfusion injury have rendered it difficult to develop satisfactory treatment approaches for this health problem. Various studies have shown that damage caused by myocardial ischemia-reperfusion can be prevented or limited by non-pharmacological strategies such as ischemic pre-conditioning, ischemic post-conditioning, and remote ischemic conditioning, as well as hyperthermia (15).

Ischemic pre-conditioning. The phenomenon of ischemic pre-conditioning refers to a therapeutic approach whereby repeated short episodes of ischemia protect the myocardium against a subsequent total occlusion of the coronary artery. This approach has been recognized as the strongest form of in vivo protection against myocardial ischemic injury, since it is most consistent and the magnitude of protection achieved is larger than that from any other intervention. It has been suggested that such pre-conditioning has significant application prior to cardiac surgery. A brief period of ischemia protects the heart from more prolonged episodes of ischemia, and reduce not only the infarct size but also its incidence, and also minimize severity of reperfusion-induced arrhythmias, preventing endothelial cell dysfunction (16).

The mechanism underlying ischemic pre-conditioning is very complex and is probably associated with the activation of certain G-protein-coupled receptors (GPCR). There is also evidence indicating the transactivation of receptor tyrosine kinase activity, and the PI3K/Akt signaling pathway. As briefly illustrated in Fig. 2, activation of GPCR and PI3K/Akt leads to elevated activity of nitric oxide synthase (NOS) and nitric oxide (NO) formation, as well as guanylate cyclase and protein kinase $\mathrm{G}$ (PKG). Substrates for PKG include the SR regulatory protein phospholamban, which promotes $\mathrm{SR} \mathrm{Ca}^{2+}$ uptake, and thus reduces cytosolic $\mathrm{Ca}^{2+}$ overload and inhibition of mPTP. Activation of Akt also inhibits GSK-3 $\beta$ and pro-apoptosis members of the Bcl-2 protein family such as Bad and Bim, thereby inhibiting mPTP opening.

Ischemic post-conditioning. The phenomenon of ischemic post-conditioning encompasses introduction of brief cycles of ischemia/reflow soon after the damaging prolonged ischemia followed by reperfusion (17). Ischemic post-conditioning has been shown to reduce infarct size, in some cases, equivalent to that observed with ischemic pre-conditioning. In general, the protection afforded by ischemic post-conditioning is weak or absent after brief ischemic episodes that cause small infarcts (18). However, unlike ischemic pre-conditioning, which delays the development of infarction, post-conditioning reduces reperfusion injury. Although no standard operating procedures have been defined, the post-conditioning intervention must be done within the first few minutes following reperfusion after ischemia. The mechanism by which 


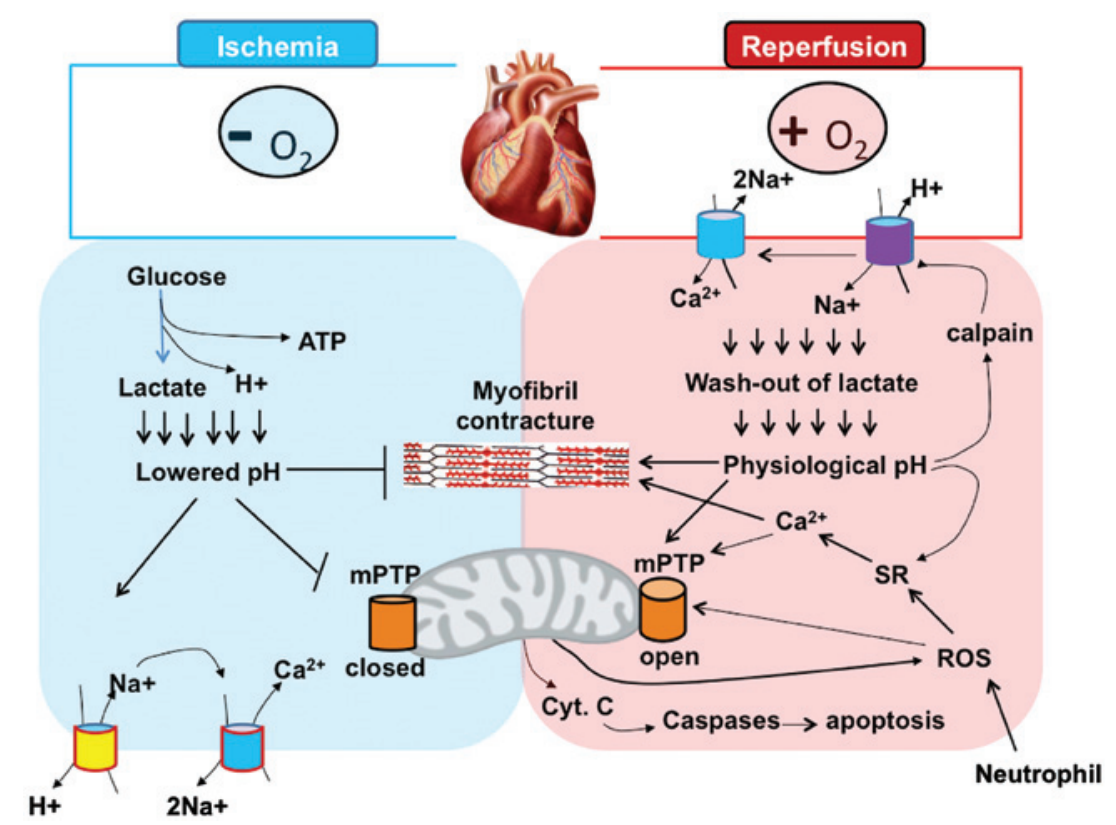

Figure 1. The main proponents of myocardial ischemia-reperfusion injury. mPTP, mitochondrial permeability transition pore; SR, sarcoplasmic reticulum; Cyt c, cytochrome c.

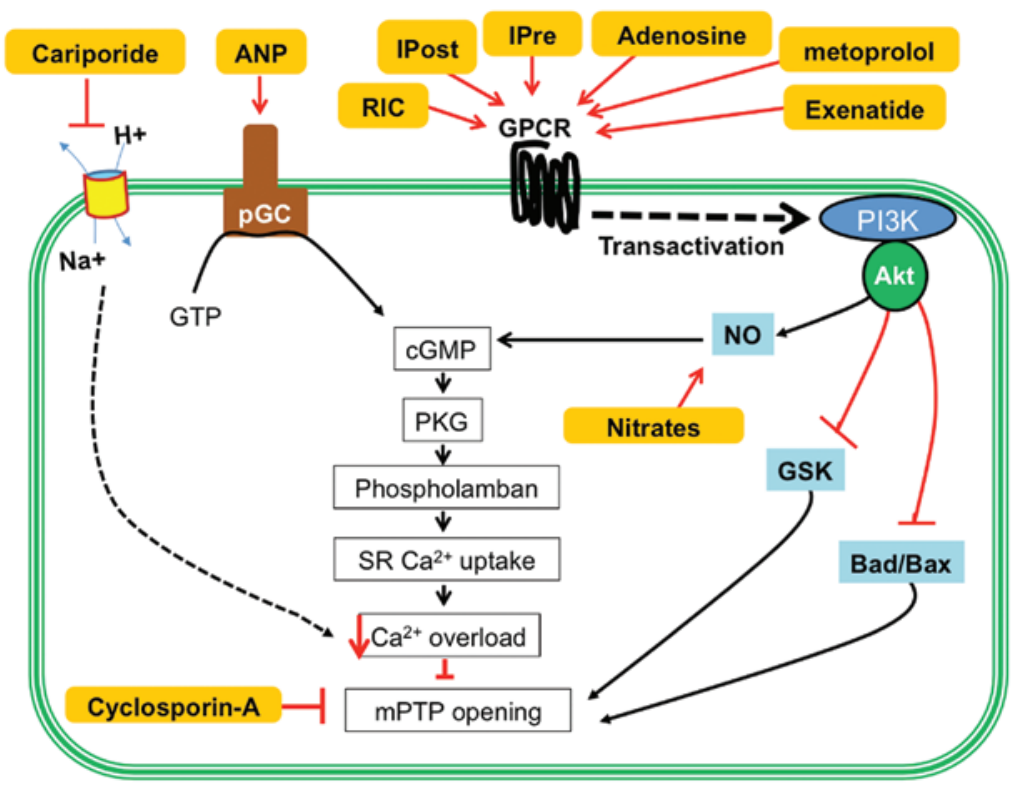

Figure 2. The more promising strategies for combating myocardial ischemia-reperfusion injury. ANP, atrial natriuretic peptide; cGMP, cyclic guanylate monophosphate; GTP, guanosine triphosphate; IPre, ischemic preconditioning; IPost, ischemic postconditioning; NO, nitric oxide; pGC, particular guanylate cyclase; PKG, protein kinase G; RIC, remote ischemic conditioning; mPTP, mitochondrial permeability transition pore.

post-conditioning reduces reperfusion injury is less understood. Several autacoids and kinases appear to share common roles in classic pre- and post-conditioning (Fig. 2). Post-conditioning probably provides the protective effect mainly by its ability to delay the normalization of intracellular $\mathrm{pH}$ for few minutes, by slowing metabolite washout, secondary to flow interruptions. These flow interruptions also reduce oxidative damage and preserve the NO-cGMP-PKG signaling pathway and inhibit $\mathrm{Na}^{+} / \mathrm{H}^{+}$exchange and thus $\mathrm{Ca}^{2+}$ overload $(19,20)$.

Remote ischemic conditioning. The phenomenon of remote ischemic conditioning refers to the protection of the heart against acute ischemia-reperfusion injury by applying brief episodes of non-lethal ischemia and reperfusion to another organ or tissue. In this approach, the therapeutic intervention is applied away from the heart, to another organ or tissue, thereby facilitating its clinical application (21). The procedure is non-invasive and can be applied before and during sustained ischemia and the onset of reperfusion. In fact, remote ischemic conditioning can be achieved simply by inflating and deflating a blood pressure cuff placed around the upper arm and inducing three 5-min cycles of ischemia and reflow (21). Such therapeutic intervention has been reported to be beneficial in patients undergoing cardiac surgery (22). 
The infarct-size-limiting effects of remote conditioning have been shown to be comparable to the effects of ischemic post-conditioning (23). Although the mechanism by which remote ischemic conditioning approach exerts cardiac protection is not clear, two major hypotheses have been proposed: i) The neural hypothesis, which states that autocoids released from the remote ischemic organ affect the local afferent neural pathway, which in turn, activates the efferent neural pathways to trigger end organ protection; and ii) the humoral hypothesis, which states that autocoids released from the ischemic remote organ are transported to the end organ, the heart, resulting in the activation of kinase signaling pathways, such as PI3K/Akt (24).

Rapid cooling. Therapeutic hypothermia, from mild hypothermia $\left(32-35^{\circ} \mathrm{C}\right)$, to moderate $\left(28-32^{\circ} \mathrm{C}\right)$, severe $\left(20-28^{\circ} \mathrm{C}\right)$, and profound $\left(<20^{\circ} \mathrm{C}\right)$ hypothermia is shown to be beneficial against myocardial reperfusion injury in animal studies $(25,26)$. These studies have revealed that lowering myocardial temperature during ischemia can limit infarct size via reductions in metabolic demand, inflammatory response, platelet aggregation, and by increasing myocardial efficiency. However, translation of these beneficial effects to humans in clinical trials met with limited success and this is mostly attributed to the cooling devices used, such as endovascular heat exchange devices, which take considerable time to induce reduction in core temperatures. Consequently, in clinical studies employing such devices, only a minority of patients were able to reach the target temperature of $<35^{\circ} \mathrm{C}$ before reperfusion. In a pilot study described by Götberg et al (27) patients were randomly exposed to hypothermia induced by intravenous infusion of cold saline before reperfusion and all patients could attain a core body temperature of $<35^{\circ} \mathrm{C}$ before reperfusion and had reduction in infarct size (27). In addition, no increase in adverse events was seen. This pilot study demonstrated that attaining a core body temperature of $<35^{\circ} \mathrm{C}$ rapidly may be effective in reducing myocardial infarct size and can be quickly and safety induced without a significant delay in reperfusion.

\section{Pharmacological cardioprotective approaches}

Elucidation of the mechanistic basis for myocardial ischemia-reperfusion injury in various studies has resulted in the identification of various pharmacological agents to protect the heart. Some of the most promising cardioprotective strategies are shown in Fig. 2.

$\mathrm{Na}^{+} / \mathrm{H}^{+}$exchange inhibitors. The build up of intracellular calcium resulting from the inhibition of $\mathrm{Na}^{+} / \mathrm{K}^{+}$-ATPase and by the hyperactivation of $\mathrm{Na}^{+} / \mathrm{H}^{+}$exchanger in cardiomyocytes during ischemia and reperfusion, is the rationale for the use of $\mathrm{Na}^{+} / \mathrm{H}^{+}$exchange inhibitors, to protect the heart from ischemia-reperfusion injury. Cariporide has been extensively studied and it demonstrated an attenuation of reperfusion injury characterized by improved LV function (28). SM-20550, another $\mathrm{Na}^{+} / \mathrm{H}^{+}$exchange inhibitor, was compared with nicorandil, a K-channel opener with nitrate-like activity. Both reduced infarct size in a dose-dependent manner when given pre-ischemia but only SM-20550 was beneficial when given post-ischemia (29). Besides the cardioprotective effects, several lines of evidence indicates that $\mathrm{Na}^{+} / \mathrm{H}^{+}$exchange inhibition is also effective to minimize myocardial remodelling (30).

Atrial natriuretic peptide (ANP) and phosphodiesterase 5 (PDE5) inhibitors. Animal studies have demonstrated that inclusion of ANP during reperfusion reduces infarct size through the activation of cGMP/PKG signaling pathway (31), PKG, when activated by cGMP, phosphorylates several intracellular target proteins that are involved in the regulation of vascular tone, vasorelaxation in vascular smooth muscle and also endothelial permeability, and cell differentiation and proliferation. Targeting this pro-survival signaling pathway of cGMP/PKG for the prevention of myocardial reperfusion injury also has evidence from studies using inhibitors of (PDE enzymes, in particular PDE5, which blocks the hydrolysis of cGMP. Thus PDE5 inhibitors such as sildenafil, vardenafil, and tadalafil have been shown to be protective against myocardial ischemia/reperfusion injury, by inducing the expression of NOS, and activation of PKG-dependent hydrogen sulfide generation. There have been several clinical studies indicating the beneficial effects of PDE5 inhibitors, which appear to act similarly to cardiac pre-conditioning (32). In studies on pigs, reduction in the infarct size and improvement in ventricular function has been shown by intravenous ANP administration at the time of reperfusion following myocardial ischemia (33).

Glucose-insulin-potassium (GIK). Insulin administration also acts through the cGMP/PKG signaling pathway, as well as by increasing glucose use (34). Experimental animal studies have shown that promoting anabolic utilization of glucose by myocardium, using insulin during acute myocardial ischemia is beneficial for the heart (35). A large number of clinical trials have investigated the effect of this therapeutic approach using GIK. Despite mixed results, it appears that GIK therapy may be more effective to reduce infarct size as well as serious electrical complications when administered in the ambulance to patients with MI that will receive primary angioplasty (36).

Glucagon-like peptide-1(GLP-1). The insulinotropic incretin, GLP-1 and its analogue exenatide have been shown to offer protection during ischemia-reperfusion $(37,38)$. This therapeutic approach has successfully been translated into the clinical setting, employing exenatide during reperfusion (39).

Adenosine receptor agonists. Adenosine and other adenosine receptor agonists have been studied in numerous experimental models and some, but not all, showed cardioprotective effects. A variety of mechanisms of action of a cardioprotective effect for adenosine has been suggested, including a potent vasodilatory action, among others. In addition to its effects on the vasculature and leukocytes, adenosine increases NO availability via activation of Akt/cGMP/PKG signaling pathway. This autocoid has been evaluated intravenously in several trials (40) without conclusive results, although evidence was obtained for cardiac protection at high dose of adenosine, in patients with previous infarctions (41). However, a subsequent double-blind study with 200 patients revealed that even though not all patients benefit from adenosine to limit infarct size, this goal could be achieved in patients receiving primary 
angioplasty within the first $3 \mathrm{~h}$ after the onset of pain (42). These patients also showed an improvement in LV ejection fraction during the first 6 months after the infarction. Since intracoronary adenosine is a safe and inexpensive treatment, its early use in reperfused patients could be easily adopted if later studies confirm the benefits.

mPTP inhibitors. Cyclosporine-A is the first pharmacologic agent that has been shown to limit infarct size by inhibiting the opening of the mPTP. Although other indirect mPTP inhibitors, including sodium nitrite, bendavia, and TRO40303 have been described, cyclosporine-A remains the most promising intervention. In a first pilot study, cyclosporine-A limited infarct size in 58 patients with MI undergoing primary angioplasty (43). Even though another study with similar number of patients found no benefit in clinical outcomes (44), the current concern is to know whether this therapeutic approach can reduce death, hospitalization for heart failure, and LV remodeling. Also the negative results from a recent multi center study on the ability of cyclosporine to contain the reperfusion injury and infarct size were questioned by the possible differences in the vehicle used for cyclosporine administration (45).

$\beta$-blockers. The beneficial effect of $\beta$-blockers on LV remodeling, reinfarction, life-threatening arrhythmias, and most importantly, mortality are well documented. However, their effect on infarct size is somewhat more controversial, and preclinical evidence on the use of $\beta$-blockers for reducing infarct size is mixed. From the 1970s to 1980 s, different $\beta$-blockers were tested with no definite conclusion on their cardioprotective effect. These trials were performed before reperfusion became established practice. Preclinical data from the pig model of MI demonstrated that intravenous injection of metoprolol significantly reduced infarct size when administered before reperfusion (46). The mechanism responsible for this infarct-limiting effect is proposed to be related to the effect of metoprolol on circulating cells such as neutrophils and platelets, rather than cardiomyocytes (47). This pre-clinical evidence led to a clinical study aimed to determine the effect of intravenous metropolol, administered immediately before primary angioplasty, on infarct size determined with magnetic resonance imaging and the results showed protection via an increase in myocardial salvage without complications (48). Although there is excitement about the cardioprotective potential of new $\beta$-blockers such as nebivolol (49), sufficient pre-clinical investigation, including reproducible results in multiple animal models, should be completed before large-scale clinical testing. Majority of the earlier clinical trials that looked at the efficacy of $\beta$-blockers in MI were carried out in the pre-thrombolytic era, and the consensus from these studies was that $\beta$-blockers might reduce infarct size when given very early after the onset of symptoms.

Glycoprotein IIb/IIIa inhibitors. Glycoprotein IIb/IIIa inhibitors were developed for the reduction of thrombotic events due to their potent effect on platelets and platelet-leukocyte aggregates implicated in ischemia-reperfusion injury. Most of the clinical trials employed abciximab, the potent glycoprotein IIb/IIIa inhibitor, and it was suggested that abciximab could reduce myocardial infarct size and lead to improved clinical outcomes when administered early to patients with myocardial infarct (50) or when given via an intracoronary route compared with intravenous route (51). This benefit may be related to reduction in platelet aggregation, thus keeping the infarct-related coronary artery patent. However, it has been noted that certain antiplatelet agents, such as clopidogrel and cangrelor, reduce myocardial infarct size and prevent myocardial reperfusion injury when administrated at the time of myocardial reperfusion in ischemia-reperfusion models that do not primarily involve in formation of thrombus as the cause of the coronary occlusion but induce ischemia mechanically (52). Therefore, antiplatelet therapy given to MI patients undergoing percutaneous coronary intervention may be cardioprotective through some pleitropic mechanisms. Currently, the standard of care for MI patients includes potent oral antiplatelet agents primarily and glycoprotein IIb/IIIa inhibitors are prescribed for a selected MI population. Comparison of two different glycoprotein IIb/IIIa inhibitors, abciximab and eptifibatide, has revealed that abciximab was superior to eptifibatide in improving angiographic and electrocardiographic assessment of coronary perfusion, as well as in reducing infarct size (53).

Nitrates and nitroglycerin. Although early clinical trial in the pre-thrombolytic era of the 1970s and 1980s suggested that nitrates could reduce mortality in the setting of MI, large clinical trials failed to confirm this benefit (54). Nevertheless, there is renewed interest in nitrates as a cardioprotectant in recent years because new clinical and animal model studies have shown promising results. Several recent clinical studies have shown the potential of nitrates to limit myocardial infarct size. A retrospective analysis of the Global Registry of Acute Coronary Syndromes data set aiming to determine if antecedent nitrate therapy led to less myocardial necrosis during the ischemic event, has revealed that $18 \%$ of chronic nitrate users were diagnosed with MI compared with $41 \%$ of nitrate-naive patients (55). Similarly, $82 \%$ of nitrate users presented with non-MI compared with $59 \%$ of patients who were nitrate naive. Moreover, nitroglycerin used as nitrate, was associated with lower tropin levels, regardless of acute coronary syndrome type. Nitroglycerin has also been shown to have pre-conditioning mimetic action in several clinical circumstances. In patients with stable angina, pre-treatment with nitroglycerin $24 \mathrm{~h}$ before an exercise tolerance test improved functional capacity and electrocardiographic manifestations of ischemia. Patients who received nitroglycerin had improvement in ST-segment shifts, regional wall motion abnormalities, and chest pain score after balloon inflation compared with patients who received saline (56).

\section{Conclusion}

Myocardial ischemia-reperfusion injury is a complex event with many interlinked processes. Approaches to combat this phenomenon are not adequately developed. Indeed, an agent that aids in the reduction of myocardial ischemia-reperfusion injury might only address one aspect of the pathological condition. In addition, therapeutic attempts to minimize the damage by targeting individual players of the process have shown promise in the laboratory, but have been less encouraging in clinical application. It is important that a potential course of 
treatment involves a variety of intervening mechanisms that are appropriately timed to ensure a complete protection from ischemia-reperfusion injury.

\section{References}

1. Callender T, Woodward M, Roth G, Farzadfar F, Lemarie JC, Gicquel S, Atherton J, Rahimzadeh S, Ghaziani M, Shaikh M, et al: Heart failure care in low- and middle-income countries: A systematic review and meta-analysis. PLoS Med 11: e1001699, 2014.

2. Ibáñez B, Heusch G, Ovize M and Van de Werf F: Evolving therapies for myocardial ischemia/reperfusion injury. J Am Coll Cardiol 65: 1454-1471, 2015.

3. Yellon DM and Hausenloy DJ: Myocardial reperfusion injury. N Engl J Med 357: 1121-1135, 2007.

4. Eapen ZJ, Tang WH, Felker GM, Hernandez AF, Mahaffey KW, Lincoff AM and Roe MT: Defining heart failure end points in ST-segment elevation myocardial infarction trials: Integrating past experiences to chart a path forward. Circ Cardiovasc Qual Outcomes 5: 594-600, 2012.

5. Reeve JL, Duffy AM, O'Brien T and Samali A: Don't lose heart - therapeutic value of apoptosis prevention in the treatment of cardiovascular disease. J Cell Mol Med 9: 609-622, 2005.

6. Piper HM, García-Dorado D and Ovize M: A fresh look at reperfusion injury. Cardiovasc Res 38: 291-300, 1998.

7. Cannon RO III: Mechanisms, management and future directions for reperfusion injury after acute myocardial infarction. Nat Clin Pract Cardiovasc Med 2: 88-94, 2005.

8. Reimer KA, Jennings RB and Tatum AH: Pathobiology of acute myocardial ischemia: Metabolic, functional and ultrastructural studies. Am J Cardiol 52: 72A-81A, 1983.

9. Ladilov YV, Siegmund B and Piper HM: Protection of reoxygenated cardiomyocytes against hypercontracture by inhibition of $\mathrm{Na}^{+} / \mathrm{H}^{+}$exchange. Am J Physiol 268: H1531-H1539, 1995.

10. Inserte J, Hernando V and Garcia-Dorado D: Contribution of calpains to myocardial ischaemia/reperfusion injury. Cardiovasc Res 96: 23-31, 2012.

11. Ruiz-Meana M, García-Dorado D, González MA, Barrabés JA and Soler-Soler J: Effect of osmotic stress on sarcolemmal integrity of isolated cardiomyocytes following transient metabolic inhibition. Cardiovasc Res 30: 64-69, 1995.

12. Barrabés JA, Garcia-Dorado D, Ruiz-Meana M, Piper HM, Solares J, González MA, Oliveras J, Herrejón MP and Soler Soler J: Myocardial segment shrinkage during coronary reperfusion in situ. Relation to hypercontracture and myocardial necrosis. Pflugers Arch 431: 519-526, 1996.

13. Halestrap AP, Clarke SJ and Javadov SA: Mitochondrial permeability transition pore opening during myocardial reperfusion - a target for cardioprotection. Cardiovasc Res 61: 372-385, 2004.

14. Ruiz-Meana M, Inserte J, Fernandez-Sanz C, Hernando V, Miro-Casas E, Barba I and Garcia-Dorado D: The role of mitochondrial permeability transition in reperfusion-induced cardiomyocyte death depends on the duration of ischemia. Basic Res Cardiol 106: 1259-1268, 2011.

15. Buja LM: Myocardial ischemia and reperfusion injury. Cardiovasc Pathol 14: 170-175, 2005.

16. Heusch G: Cardioprotection: Chances and challenges of its translation to the clinic. Lancet 381: 166-175, 2013.

17. Zhao ZQ, Corvera JS, Halkos ME, Kerendi F, Wang NP, Guyton RA and Vinten-Johansen J: Inhibition of myocardial injury by ischemic postconditioning during reperfusion: Comparison with ischemic preconditioning. Am J Physiol Heart Circ Physiol 285: H579-H588, 2003.

18. Rodríguez-Sinovas A, Cabestrero A, García del Blanco B, Inserte J, García A and García-Dorado D: Intracoronary acid infusion as an alternative to ischemic postconditioning in pigs. Basic Res Cardiol 104: 761-771, 2009.

19. Inserte J, Ruiz-Meana M, Rodríguez-Sinovas A, Barba I and Garcia-Dorado D: Contribution of delayed intracellular $\mathrm{pH}$ recovery to ischemic postconditioning protection. Antioxid Redox Signal 14: 923-939, 2011.

20. Inserte J, Barba I, Poncelas-Nozal M, Hernando V, Agulló L, Ruiz-Meana M and Garcia-Dorado D: cGMP/PKG pathway mediates myocardial postconditioning protection in rat hearts by delaying normalization of intracellular acidosis during reperfusion. J Mol Cell Cardiol 50: 903-909, 2011.
21. Hausenloy DJ and Yellon DM: Remote ischaemic preconditioning: Underlying mechanisms and clinical application. Cardiovasc Res 79: 377-386, 2008.

22. Thielmann M, Wendt D, Tsagakis K, Price V, Dohle DS, Pasa $\mathrm{S}$ and Kottenberg E: Remote ischemic preconditioning: The surgeon's perspective. J Cardiovasc Med (Hagerstown) 14: 187-192, 2013.

23. Gritsopoulos G, Iliodromitis EK, Zoga A, Farmakis D, Demerouti E, Papalois A, Paraskevaidis IA and Kremastinos DT: Remote postconditioning is more potent than classic postconditioning in reducing the infarct size in anesthetized rabbits. Cardiovasc Drugs Ther 23: 193-198, 2009.

24. Hausenloy DJ, Iliodromitis EK, Andreadou I, Papalois A, Gritsopoulos G, Anastasiou-Nana M, Kremastinos DT and Yellon DM: Investigating the signal transduction pathways underlying remote ischemic conditioning in the porcine heart Cardiovasc Drugs Ther 26: 87-93, 2012.

25. Tissier R, Chenoune M, Ghaleh B, Cohen MV, Downey JM and Berdeaux A: The small chill: Mild hypothermia for cardioprotection? Cardiovasc Res 88: 406-414, 2010.

26. Hale SL and Kloner RA: Mild hypothermia as a cardioprotective approach for acute myocardial infarction: Laboratory to clinical application. J Cardiovasc Pharmacol Ther 16: 131-139, 2011.

27. Götberg M, Olivecrona GK, Koul S, Carlsson M, Engblom H, Ugander M, van der Pals J, Algotsson L, Arheden H and Erlinge D: A pilot study of rapid cooling by cold saline and endovascular cooling before reperfusion in patients with ST-elevation myocardial infarction. Circ Cardiovasc Interv 3: 400-407, 2010.

28. Rupprecht HJ, vom Dahl J, Terres W, Seyfarth KM, Richardt G, Schultheibeta HP, Buerke M, Sheehan FH and Drexler H: Cardioprotective effects of the $\mathrm{Na}(+) / \mathrm{H}(+)$ exchange inhibitor cariporide in patients with acute anterior myocardial infarction undergoing direct PTCA. Circulation 101: 2902-2908, 2000.

29. Yamada K, Matsui K, Satoh K, Kitano M, Yamamoto S and Ohashi N: Reduction of myocardial infarct size by SM-20550, a novel $\mathrm{Na}(+) / \mathrm{H}(+)$ exchange inhibitor, in rabbits. Eur $\mathrm{J}$ Pharmacol 404: 201-212, 2000.

30. Karmazyn M: NHE-1: Still a viable therapeutic target. J Mol Cell Cardiol 61: 77-82, 2013.

31. Yang XM, Philipp S, Downey JM and Cohen MV: Atrial natriuretic peptide administered just prior to reperfusion limits infarction in rabbit hearts. Basic Res Cardiol 101: 311-318, 2006.

32. Das A, Durrant D, Salloum FN, Xi L and Kukreja RC: PDE5 inhibitors as therapeutics for heart disease, diabetes and cancer. Pharmacol Ther 147: 12-21, 2015.

33. Padilla F, Garcia-Dorado D, Agulló L, Barrabés JA, Inserte J, Escalona N, Meyer M, Mirabet M, Pina P and Soler-Soler J: Intravenous administration of the natriuretic peptide urodilatin at low doses during coronary reperfusion limits infarct size in anesthetized pigs. Cardiovasc Res 51: 592-600, 2001.

34. Gao F, Gao E, Yue TL, Ohlstein EH, Lopez BL, Christopher TA and Ma XL: Nitric oxide mediates the antiapoptotic effect of insulin in myocardial ischemia-reperfusion: The roles of PI3-kinase, Akt, and endothelial nitric oxide synthase phosphorylation. Circulation 105: 1497-1502, 2002.

35. Suranadi IW, Demaison L, Chaté V, Peltier S, Richardson M and Leverve X: An increase in the redox state during reperfusion contributes to the cardioprotective effect of GIK solution. J Appl Physiol (1985) 113: 775-784, 2012.

36. Selker HP, Beshansky JR, Sheehan PR, Massaro JM, Griffith JL, D'Agostino RB, Ruthazer R, Atkins JM, Sayah AJ, Levy MK, et al: Out-of-hospital administration of intravenous glucose-insulin-potassium in patients with suspected acute coronary syndromes: The IMMEDIATE randomized controlled trial. JAMA 307: 1925-1933, 2012.

37. Ban K, Noyan-Ashraf MH, Hoefer J, Bolz SS, Drucker DJ and Husain M: Cardioprotective and vasodilatory actions of glucagon-like peptide 1 receptor are mediated through both glucagon-like peptide 1 receptor-dependent and -independent pathways. Circulation 117: 2340-2350, 2008.

38. Timmers L, Henriques JP, de Kleijn DP, Devries JH, Kemperman H, Steendijk P, Verlaan CW, Kerver M, Piek JJ, Doevendans PA, et al: Exenatide reduces infarct size and improves cardiac function in a porcine model of ischemia and reperfusion injury. J Am Coll Cardiol 53: 501-510, 2009.

39. Lønborg J, Vejlstrup N, Kelbæk H, Bøtker HE, Kim WY, Mathiasen AB, Jørgensen E, Helqvist S, Saunamäki K, Clemmensen $\mathrm{P}$, et al: Exenatide reduces reperfusion injury in patients with ST-segment elevation myocardial infarction. Eur Heart J 33: 1491-1499, 2012. 
40. Mahaffey KW, Puma JA, Barbagelata NA, DiCarli MF, Leesar MA, Browne KF, Eisenberg PR, Bolli R, Casas AC, Molina-Viamonte $\mathrm{V}$, et al: Adenosine as an adjunct to thrombolytic therapy for acute myocardial infarction: results of a multicenter, randomized, placebo-controlled trial: the Acute Myocardial Infarction STudy of ADenosine (AMISTAD) trial. J Am Coll Cardiol 34: 1711-1720, 1999.

41. Ross AM, Gibbons RJ, Stone GW, Kloner RA and Alexander RW AMISTAD-II Investigators: A randomized, double-blinded, placebo-controlled multicenter trial of adenosine as an adjunct to reperfusion in the treatment of acute myocardial infarction (AMISTAD-II). J Am Coll Cardiol 45: 1775-1780, 2005.

42. Garcia-Dorado D, García-del-Blanco B, Otaegui I, Rodríguez-Palomares J, Pineda V, Gimeno F, Ruiz-Salmerón R, Elizaga J, Evangelista A, Fernandez-Avilés F, et al: Intracoronary injection of adenosine before reperfusion in patients with ST-segment elevation myocardial infarction: A randomized controlled clinical trial. Int J Cardiol 177: 935-941, 2014.

43. Piot C, Croisille P, Staat P, Thibault H, Rioufol G, Mewton N, Elbelghiti R, Cung TT, Bonnefoy E, Angoulvant D, et al: Effect of cyclosporine on reperfusion injury in acute myocardial infarction. N Engl J Med 359: 473-481, 2008.

44. Ghaffari S, Kazemi B, Toluey M and Sepehrvand N: The effect of prethrombolytic cyclosporine-A injection on clinical outcome of acute anterior ST-elevation myocardial infarction. Cardiovasc Ther 31: e34-e39, 2013.

45. Hausenloy DJ and Yellon DM: Targeting myocardial reperfusion injury - the search continues. N Engl J Med 373: 1073-1075, 2015.

46. Ibanez B, Cimmino G, Prat-González S, Vilahur G, Hutter R, García MJ, Fuster V, Sanz J, Badimon L and Badimon JJ: The cardioprotection granted by metoprolol is restricted to its administration prior to coronary reperfusion. Int J Cardiol 147: 428-432, 2011

47. García-Prieto J, García-Ruiz JM, Sanz-Rosa D, Pun A, García-Alvarez A, Davidson SM, Fernández-Friera L, Nuno-Ayala M, Fernández-Jiménez R, Bernal JA, et al: $\beta 3$ adrenergic receptor selective stimulation during ischemia/reperfusion improves cardiac function in translational models through inhibition of mPTP opening in cardiomyocytes. Basic Res Cardiol 109: 422, 2014

48. Ibanez B, Macaya C, Sánchez-Brunete V, Pizarro G, Fernández-Friera L, Mateos A, Fernández-Ortiz A, García-Ruiz JM, García-Álvarez A, Iñiguez A, et al: Effect of early metoprolol on infarct size in ST-segment-elevation myocardial infarction patients undergoing primary percutaneous coronary intervention: The Effect of Metoprolol in Cardioprotection During an Acute Myocardial Infarction (METOCARD-CNIC) trial. Circulation 128: 1495-1503, 2013.
49. Sorrentino SA, Doerries C, Manes C, Speer T, Dessy C, Lobysheva I, Mohmand W, Akbar R, Bahlmann F, Besler C, et al: Nebivolol exerts beneficial effects on endothelial function, early endothelial progenitor cells, myocardial neovascularization, and left ventricular dysfunction early after myocardial infarction beyond conventional $\beta 1$-blockade. J Am Coll Cardiol 57: 601-611, 2011.

50. Rakowski T, Zalewski J, Legutko J, Bartus S, Rzeszutko L, Dziewierz A, Sorysz D, Bryniarski L, Zmudka K, Kaluza GL, et al: Early abciximab administration before primary percutaneous coronary intervention improves infarct-related artery patency and left ventricular function in high-risk patients with anterior wall myocardial infarction: A randomized study. Am Heart J 153: 360-365, 2007.

51. Thiele H, Schindler K, Friedenberger J, Eitel I, Fürnau G, Grebe E, Erbs S, Linke A, Möbius-Winkler S, Kivelitz D, et al: Intracoronary compared with intravenous bolus abciximab application in patients with ST-elevation myocardial infarction undergoing primary percutaneous coronary intervention: The randomized Leipzig immediate percutaneous coronary intervention abciximab IV versus IC in ST-elevation myocardial infarction trial. Circulation 118: 49-57, 2008.

52. Yang XM, Liu Y, Cui L, Yang X, Liu Y, Tandon N, Kambayashi J, Downey JM and Cohen MV: Platelet P2Y(1)(2) blockers confer direct postconditioning-like protection in reperfused rabbit hearts. J Cardiovasc Pharmacol Ther 18: 251-262, 2013.

53. Bajaj RR, Mohammad A, Hong T, Irfan A, Sharieff W, Bagnall A, Christie JA, Kutryk MJ, Chisholm RJ and Cheema AN: Comparison of abciximab and eptifibatide on angiographic and clinical outcomes in rescue percutaneous coronary intervention for failed fibrinolytic therapy. J Invasive Cardiol 22: 347-352, 2010.

54. No authors listed: ISIS-4: a randomised factorial trial assessing early oral captopril, oral mononitrate, and intravenous magnesium sulphate in 58,050 patients with suspected acute myocardial infarction. ISIS-4 (Fourth International Study of Infarct Survival) Collaborative Group. Lancet 345: 669-685, 1995.

55. Ambrosio G, Del Pinto M, Tritto I, Agnelli G, Bentivoglio M, Zuchi C, Anderson FA, Gore JM, López-Sendón J, Wyman A, et al; GRACE Investigators: Chronic nitrate therapy is associated with different presentation and evolution of acute coronary syndromes: Insights from 52,693 patients in the Global Registry of Acute Coronary Events. Eur Heart J 31: 430-438, 2010.

56. Leesar MA, Stoddard MF, Dawn B, Jasti VG, Masden R and Bolli R: Delayed preconditioning-mimetic action of nitroglycerin in patients undergoing coronary angioplasty. Circulation 103: 2935-2941, 2001 